\title{
THEORY OF BENDING OF MULTI-LAYER SANDWICH PLATES
}

\author{
By \\ BOEN-DAR LIAW \\ Engineering Diploma \\ Taipei Institute of Technology \\ Taipei, Taiwan, China \\ 1958 \\ Master of Science \\ Oklahoma State University \\ Stillwater, Oklahoma \\ 1963
}

Submitted to the Faculty of the Graduate School of the Oklahoma State University in partial fulfillment of the requirements for the degree of

DOCTOR OF PHILOSOPHY

August, 1965 
OKLAHOMA

STATE UNIVERSITY

LIBRARY

DEC 81965

THEORY OF BENDING OF MULTI-LAYER

SANDWICH PLATES

Thesis Approved:

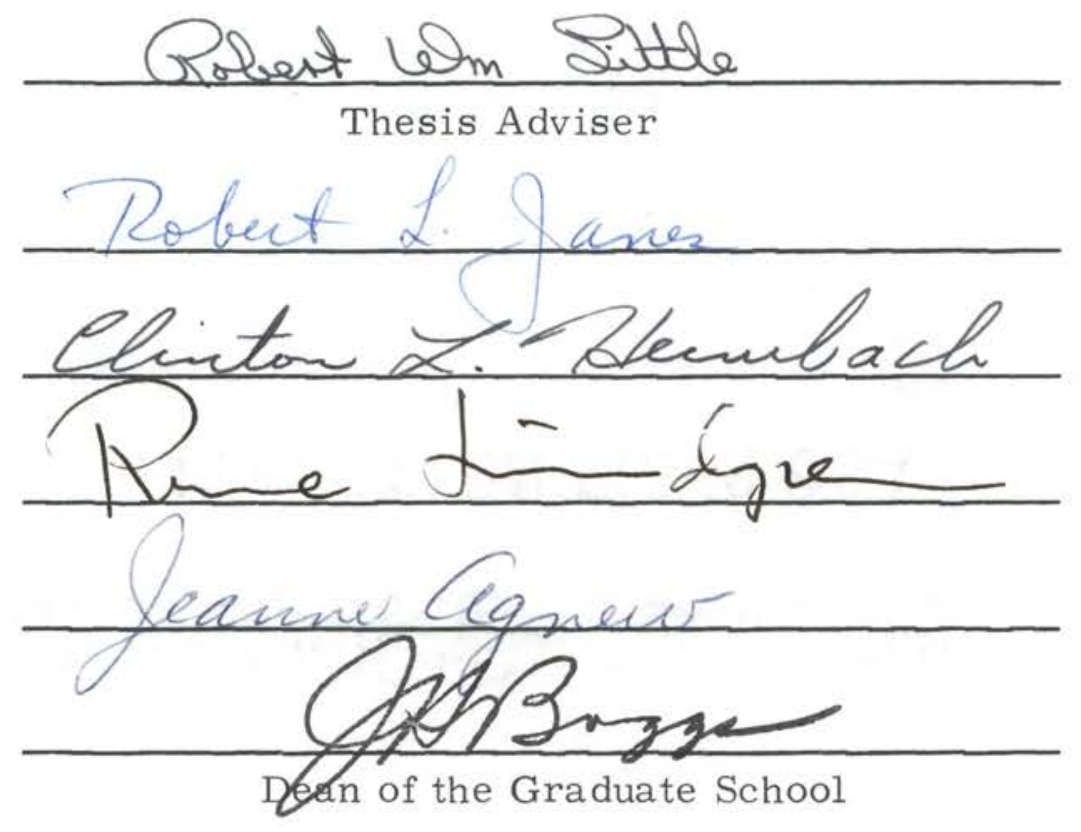

593516 


\section{ACKNOWLEDGEMENT}

The writer wishes to express his indebtedness and sincere appreciation to the following individuals and organization:

To Professor Robert Wm. Little, for his guidance and encouragement, and, most of all, for providing the inspiration and invaluable aid during the preparation of this thesis;

To Professors Jan J。 Tuma, E. Rune Lindgren, Robert L。 Janes and Jeanne L. Agnew, members of the advisory committee, for their helpful advice throughout the writer's graduate program;

To Professor J. S. Kao, for his constructive criticism and helpful assistance in preparing this thesis;

To the Facuity of the School of Civil Engineering and related departments for their valuable instruction;

To Dr。James.W. Gillespie, for his friendship, and for giving the motivation and opportunity to the writer to be gin his graduate study;

To Messrs. Julius $\mathrm{P}$ 。Wong and S. Bart Childs, for their friendship and for their kindness to bring many valuable informations to the writer's attention: 
To his wife, Claudia, and his daughter, Jean, for their unfailing patience and all the sacrifices during his years of graduate study.

In addition, gratitude is due Mrs. Peggy Harrison, who typed the manuscript.

May, 1965

Stillwater, Oklahoma

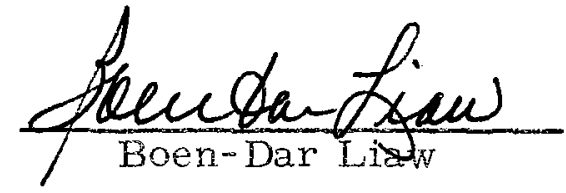




\section{TABLE OF CONTENTS}

Chapter

Page

I. INTRODUCTION ................ 1

1.1 General ............... . . 1

1.2 Historical Notes ........... 3

II. GENERAL ANALYSIS . . ............ 5

2. 1 Statement of the Problem .......... 5

2. 2 Stress Resultants and Equilibrium Equations . . 6

2.3 Equations of Compatibility .......... 8

2. 4 Boundary Conditions ........... 13

2. 5 Stresses, Moments and Shear Forces ..... 14

2.6 Specialization for Constant Poisson's Ratio . . 20

III. DERIVATION OF GOVERNING DIFFERENTIAL

EQUATIONS ............... 23

3.1 Shear Forces ............... 23

3.2 Deflection Surface ............ 26

3.3 Reduction to the Case of Isotropic Cores . . . 29

IV. A SIMPLY SUPPORTED RECTANGULAR PLATE WITH ORTHOTROPIC CORES ........。 31

V. SUMMARY AND CONCLUSIONS .......... 36

BIBLIOGRA PHY . . . . . . . . . ...... 38

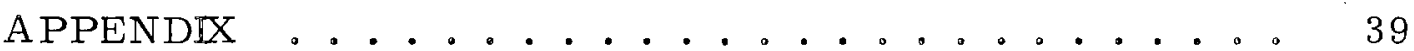




\section{LIST OF FIGURES}

Figure Page

1. A CROSS SECTION OF PLATE .......... 5

2. A DIFFERENTIAL PLATE ELEMENT. . . . . . 8

3. A SIMPLY SUPPORTED RECTANGULAR PLATE 。 . 31 


\section{NOMENCLATURE}

The following symbols have been adopted for use in this thesis:
a........... length of plate in $\mathrm{x}$ - direction;
b........... length of plate in $\mathrm{y}$ - direction;
$\mathrm{c}_{1}, \mathrm{c}_{2}, \mathrm{c}_{3}, \mathrm{c}_{4} \ldots \ldots$ some constants defined by the geometrical and material properties;
$\mathrm{C}, \mathrm{C}_{\mathrm{x}}, \mathrm{C}_{\mathrm{y}}$............. transverse shear rigidities of plate; $\mathrm{D}, \mathrm{D}_{\mathrm{xy}} \ldots \ldots \ldots . . . \quad \begin{aligned} & \text { bending and torsional rigidities of } \\ & \text { plate; }\end{aligned}$

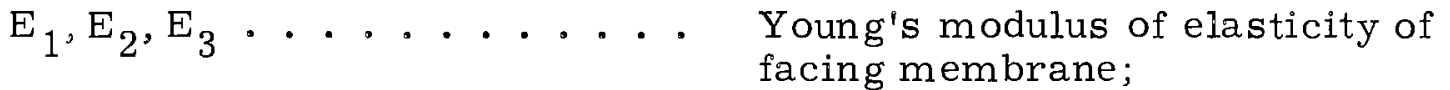
$G_{1 x z}, G_{1 y z}, G_{2 x z}, G_{2 y z}$.... shear modulus of elasticity of core;
$\mathrm{h}_{1}, \mathrm{~h}_{2} \ldots \ldots \ldots$ thickness of core;
i............. index, designates ith membrane;

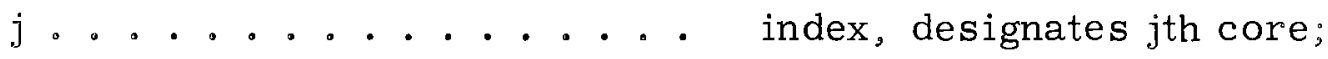
$\mathrm{K}_{1}, \mathrm{~K}_{2} \cdots \ldots$ constant defined by $\nu, \mathrm{C}_{,} \mathrm{C}_{\mathrm{x}}$ and $\mathrm{C}_{\mathrm{y}^{3}}$ $M_{x}, M_{y}, M_{x y} \cdots \cdots . . . . \quad \begin{aligned} & \text { moment, twisting moment per } \\ & \text { unit width of plate; }\end{aligned}$ $\mathrm{N}_{\mathrm{x}}, \mathrm{N}_{\mathrm{y}}, \mathrm{N}_{\mathrm{xy}} \ldots \ldots . . . . \quad \begin{aligned} & \text { stress resultant per unit width of } \\ & \text { plate; }\end{aligned}$
p........... loading function normal to the plate;
$\mathrm{Q}_{\mathrm{x}}, \mathrm{Q}_{\mathrm{y}} \ldots \ldots . . . . \quad$ shear force per unit width of plate;
$t_{1}, t_{2}, t_{3} \ldots \ldots$ thickness of facing membrane;
U............. strain energy; 


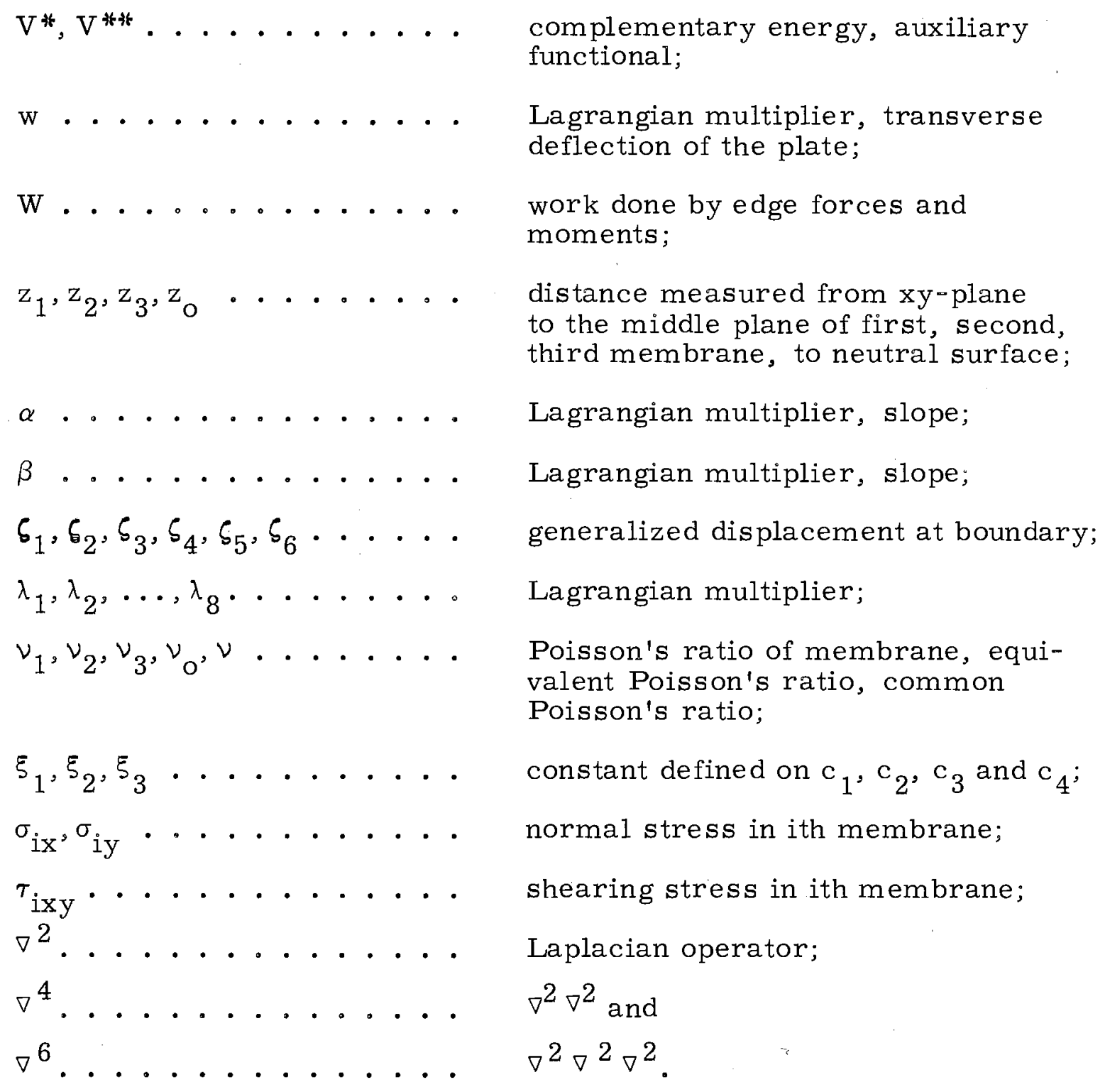

Additional symbols used in the example problem and in the Appendix are defined when they appear and are not listed. 


\section{CHAPTER I}

\section{INTRODUCTION}

\section{1 General}

A small-deflection theory for multi-core sandwich plates is developed by means of variational principles. A set of differential equations governing the deflection, moments and transverse shear forces of the plate is derived.

The sandwich constructions are characterized by the relatively low-stiffness core materials between facing membranes with high moduli of rigidities. In this investigation, the facing materials are considered to be isotropic and homogeneous. However, the different cores possess different elastic properties and, in general, are assumed to be orthotropic. The reduction to the case of isotropic cores is also shown. All deflections are defined on neutral surface, and considered that the transverse deflection of the upper and lower surfaces, at any location on the plate, are the same as that of neutral surface。

In addition to above general description concerning the property of this type of construction, the following assumptions are essentially necessary for this analysis:

(a) The total thickness is still small in comparison with the dimensions in other directions, i.e., the plates are considered to be "thin" plates. 
(b) Under all kinds of loadings, all bonds between each layer are considered strong enough so that no bond failure may occur and stresses can be transmitted without discontinuity.

(c) Non-homogeneity of the core cell is neglected.

(d) The transverse rigidities of the core materials are relatively high compared to the facing materials, i.e., transverse shear forces are completely taken by cores.

(e) The core stiffnesses associated with plane stress components in the plane of structure are neglected.

(f) The deformations due to temperature change are not taken into account in this presentation.

The development of the theory falls mainly on the formulation of the complementary energy functional, minimizing process and the elimination of the additional unknowns of Lagrangian multipliers. This portion of analysis forms the content of the second chapter of this thesis. The necessary constant quantities describing the cross - sectional property of the sandwich plate are also defined. Once the set of Euler equations is obtained, the eliminating process can proceed to obtain the differential equations governing the transverse shear forces, bending and torsional moments and the transverse deflection of the plate. Reductions to the particular case of single core sandwich plate and to the ordinary isotropic homogeneous plate equation are also shown in this third chapter. In the fourth chapter, a bending problem of this type of construction with particular edge conditions subjected to a general system of loads is solved to illustrate the application 
of the developed theory. Summary and conclusions of this study, as well as the desirable extension, are included in the final chapter.

The letter symbols adopted for use in this thesis are defined where they first appear and are listed in the Nomenclature.

1.2 Historical Notes

The analytic study of the sandwich construction becomes increasingly important with the development of new and high strength materials and the complexity of the aeronautic structures. The vast majority of past effort connected with this study has been confined to a single-core construction with two either identical or different facing plates.

The first analytic investigation which appeared in the literature associated with this problem was done by E. Reissner ${ }^{(1)}$ in $1947^{*}$. He considered a plate consisting of a core layer with two facing membranes identical both in thickness and elastic properties, and assumed that the face-parallel stresses in the core and the variation of the face stresses over the thickness of the face layers are negligible. The same assumptions were also made by N. J. Hoff ${ }^{(2)}$, but in a more general form for solving the buckling problem. This Reissner-Hoff assumption is one of the main approaches in analyzing this type of construction, and will be adopted as the basic assumption of this dissertation. For non-isotropic sandwich plates, C. Libove and S. B. Batdorf ${ }^{(3)}$ considered the sandwich plate approximately as a non-isotropic thick plate

\footnotetext{
* Numbers in parenthesises refer to references in Bibliography.
} 
and extended the classical thin plate theory to sandwich panels by introducing the effective bending and shearing rigidities, and taking the shear deformation into account. In 1951, A. C. Eringen (4) extended this theory to include the flexural rigidity of core in his investigation. Since 1959, in a series of publications, $Y . Y . Y u^{(5),(6),(7)}$ presented a flexural theory, for the isotropic case, to include the shear deformations in the facing materials. Theoretically, his investigation has generalized the Reissner-Hoff's "membrane facings" to the "platefacings" theory.

In the period between E. Reissner and $Y$. Y. Yu, a great deal of works had been done by many investigators. However, most of these studies are limited to particular problems which are still based on "membrane facings" theory, and also are confined in single core sandwich constructions. Their contributions are not in the development of the theory, but in the techniques of solving the problems. For instance, S. Cheng ${ }^{(8)}$ modified Reissner's problem for or thotropic cores and related the solution of the sandwich plate equation to the solutions of the biharmonic equation of classical plate theory. In 1960, C. C. Chang and I. K. Ebicoglu ${ }^{(9)}$ presented their studies on the elastic instability of rectangular sandwich panels with orthotropic cores and different face thicknesses and materials. 


\section{CHAPTER II}

\section{GENERAL ANALYSIS}

\subsection{Statement of the Problem}

A rectangular sandwich plate consisting of two cores of thicknesses $h_{1}$ and $h_{2}$ and three facing membranes of thicknesses $t_{1}$. $t_{2}$ and $t_{3}$ is considered (Fig. 1). Let the $x y$-plane be a plane parallel to the undeformed surface of the plate with $z$-axis along the normal to this plane. Also, let $z_{1}, z_{2}$ and $z_{3}$ be the distances measured from the $x y-p l a n e$ to the middle plane of each membrane respectively。 Each facing is assumed to be isotropic and homogeneous and posses sing different elastic properties, while the cores are both assumed to be or thotropic.

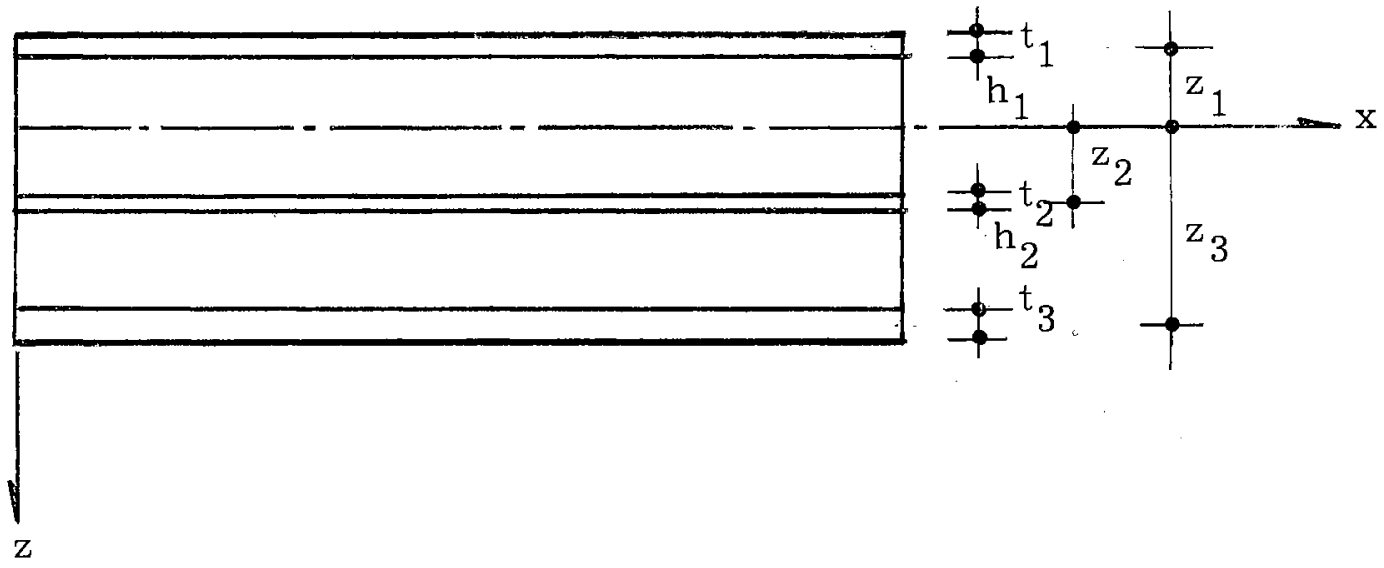

FIG. 1 A CROSS SECTION OF PLATE 
The problem to be solved is, then, to develop a theory defining the bending behavior of the sandwich plate due to a general type of externally applied load which is normal to the plate.

The formulation which will be presented in the following sections is also good for a plate with many cores. However, for simplicity in presentation, only a plate with two cores as described above will be considered.

\subsection{Stress Resultants and Equilibrium Equations}

After the assumptions made previously that the face-parallel stresses of cores and the variations of the stresses of facing membranes are negligible, the stress resultants and stress couples may be defined as follow:

$$
\begin{aligned}
& M_{x}=t_{1} z_{1} \sigma_{1 x}+t_{2} z_{2} \sigma_{2 x}+t_{3} z_{3} \sigma_{3 x} \\
& M_{y}=t_{1} z_{1} \sigma_{1 y}+t_{2} z_{2} \sigma_{2 y}+t_{3} z_{3} \sigma_{3 y} \\
& M_{x y}=t_{1} z_{1} \tau_{1 x y}+t_{2} z_{2} \tau_{2 x y}+t_{3} z_{3} \tau_{3 x y} \\
& Q_{x}=h_{1} \tau_{1 x z}+h_{2} \tau_{2 x z} \\
& Q_{y}=h_{1} \tau_{1 y z}+h_{2} \tau_{2 y z} \\
& N_{x}=t_{1} \sigma_{1 x}+t_{2} \sigma_{2 x}+t_{3} \sigma_{3 x}=0 \\
& N_{y}=t_{1} \sigma_{1 y}+t_{2} \sigma_{2 y}+t_{3} \sigma_{3 y}=0
\end{aligned}
$$




$$
\mathrm{N}_{\mathrm{xy}}=\mathrm{t}_{1}{ }_{1 \mathrm{xy}}+\mathrm{t}_{2} \tau_{2 \mathrm{xy}}+\mathrm{t}_{3} \tau_{3 \mathrm{xy}}=0
$$

where $M_{x}\left(M_{y}\right)$ designates the bending moment about $y(x)$-axis, $M_{x y}\left(=M_{y x}\right)$ the twisting moment about $y(x)$-axis, $Q_{x}\left(Q_{y}\right)$ the transverse shear force on the face normal to $x(y)$-axis, $N_{x}\left(N_{y}\right)$ the normal force on the face normal to $x(y)$-axis, $N_{x y}\left(=N_{y x}\right)$ the shear force parallel to the plane of structure and existing on the face normal to $x(y)$-direction, $\sigma_{i x}\left(\sigma_{i y}\right)$ the normal stress on ith membrane in the direction of $x(y)$-axis, $\tau_{\text {ixy }}$ the shearing stress in ith membrane parallel to $x y$-plane and $\tau_{j x z}\left(\tau_{j y z}\right)$ the shearing stress on the face normal to $\mathrm{x}(\mathrm{y})$-axis in $\mathrm{z}$-direction of $\mathrm{jth}$ core. For a problem of considering bending only, the normal forces $\mathrm{N}_{\mathrm{x}}$ and $\mathrm{N}_{\mathrm{y}}$ and the shear force $\mathrm{N}_{\mathrm{xy}}$ are not taken into account, $i_{0} \mathrm{e}_{\text {。 }}$, the stress resultants are considered to be zero.

The moments and transverse shear forces are defined on the plane of structure, as shown in Fig. 2. Summations of moments and transverse forces acting on a differential plane element $\mathrm{dxdy}$ of the plate yield the following equilibrium equations:

$$
\begin{aligned}
& M_{x, x}+M_{x y, y}-Q_{x}=0 \\
& M_{y, y}+M_{x y, x}-Q_{y}=0 \\
& Q_{x, x}+Q_{y, y}+p=0
\end{aligned}
$$

where $\mathrm{p}$ is the transverse load applied on the differential element of plate. 


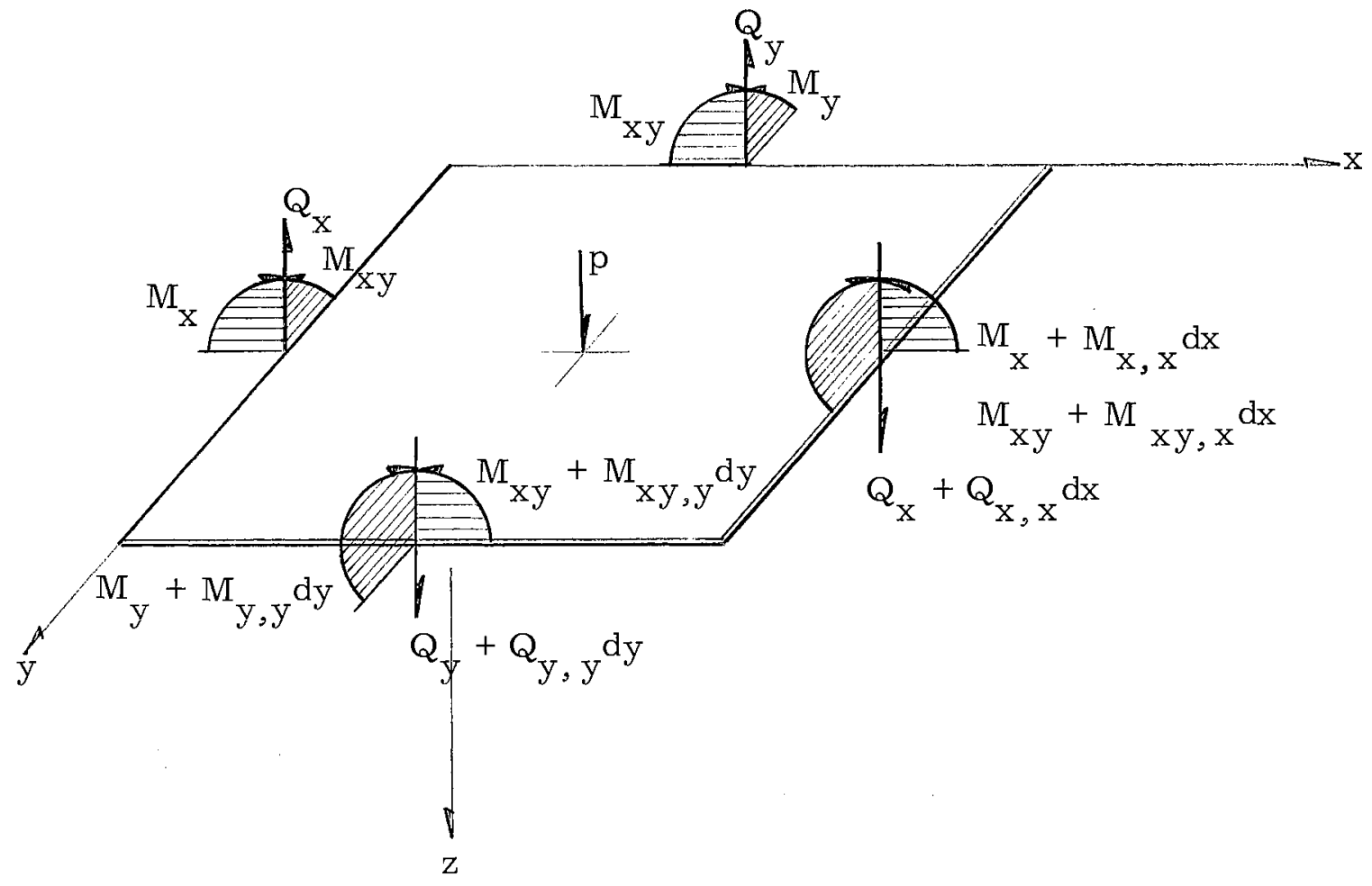

FIG。2 A DIFFERENTIAL PLATE ELEMENT

\subsection{Equations of Compatibility}

Considering a rectangular plate of the dimension a by $b$, the strain energy stored in the system after deformation is expressed in terms of stresses such as:

$$
\begin{aligned}
U=\frac{1}{2} \int_{\sigma_{f}}^{b} \int_{0}^{a}\left[\frac{t_{1}}{E_{1}}\left(\sigma_{1 x}^{2}+\sigma_{1 y}^{2}-2 \nu_{1} \sigma_{1 x} \sigma_{1 y}\right)+\frac{2 t_{1}\left(1+\nu_{1}\right)}{E_{1}} \tau_{1 x y}^{2}\right. \\
\quad+\frac{t_{2}}{E_{2}}\left(\sigma_{2 x}^{2}+\sigma_{2 y}^{2}-2 \nu_{2} \sigma_{2 x} \sigma_{2 y}\right)+\frac{2 t_{2}\left(1+\nu_{2}\right)}{E_{2}} \tau_{2 x y}^{2} \\
\left.\quad+\frac{t_{3}}{E_{3}}\left(\sigma_{3 x}^{2}+\sigma_{3 y}^{2}-2 \nu_{3} \sigma_{3 x} \sigma_{3 y}\right)+\frac{2 t_{3}\left(1+\nu_{3}\right)}{E_{3}} \tau_{3 x y}^{2}\right] d x d y
\end{aligned}
$$


$+\frac{1}{2} \int_{\mathrm{O}_{\mathrm{C}}}^{\mathrm{b}} \int_{\mathrm{O}}^{\mathrm{a}}\left[\frac{\mathrm{h}_{1}}{\mathrm{G}_{1 \mathrm{xz}}} \tau_{1 \mathrm{xz}}^{2}+\frac{\mathrm{h}_{1}}{\mathrm{G}_{1 \mathrm{yz}}} \tau_{1 \mathrm{yz}}^{2}+\frac{\mathrm{h}_{2}}{\mathrm{G}_{2 \mathrm{xz}}} \tau_{2 \mathrm{xz}}^{2}+\frac{\mathrm{h}_{2}}{\mathrm{G}_{2 \mathrm{yz}}} \tau_{2 \mathrm{yz}}^{2}\right] \mathrm{dxdy}$

where the subscript $f$ refers to the facing membranes and $c$ the cores, $\nu_{i}$ the Poisson's ratio of ith facing membrane and $G_{i x z}$ the shear modulus of rigidity of $x z-$ plane of the ith core. Let $\zeta_{1}$, $\zeta_{2}, \zeta_{3}, \zeta_{4}, \zeta_{5}$ and $\zeta_{6}$ be the generalized displacements of the plate prescribed on boundaries, the work done by the boundary forces and moments is

$$
\begin{aligned}
W & =\int_{0}^{b}\left(Q_{x} \zeta_{1}+M_{x y} \zeta_{2}+M_{x} \zeta_{3}\right)_{\substack{x=0 \\
x=a}} d y \\
& +\int_{0}^{a}\left(Q_{y} \zeta_{4}+M_{x y} \zeta_{5}+M_{y} \zeta_{6}\right)_{\substack{y=0 \\
y=b}} d x
\end{aligned}
$$

Then, the complementary energy of the system is defined as $(1)(10)$

$$
\mathrm{V}^{*}=\mathrm{U}-\mathrm{W}
$$

Thus, the problem becomes one of finding the conditions for extremum of the functional $\mathrm{V}^{*}$ subjected to the constraint conditions of equations (1), (2), (3), (4), (5), (6), (7), (8), (9), (10) and (11).

Introducing a set of Lagrangian multipliers $\lambda_{1}, \lambda_{2}, \lambda_{3}, \lambda_{4}$, $\lambda_{5}, \lambda_{6}, \lambda_{7}, \lambda_{8}, \alpha, \beta$ and $w$, the auxiliary functional can be formulated as follows: 


$$
\begin{aligned}
& \mathrm{V}^{* * * *}=\int_{0}^{\mathrm{b}} \int_{0}^{\mathrm{a}}\left\{\frac { 1 } { 2 } \left[\frac{t_{1}}{\mathrm{E}_{1}}\left(\sigma_{1 \mathrm{x}}^{2}+\sigma_{1 \mathrm{y}}^{2}-2 \nu_{1} \sigma_{1 \mathrm{x}} \sigma_{1 \mathrm{y}}\right)+\frac{2 \mathrm{t}_{1}\left(1+\nu_{1}\right)}{\mathrm{E}_{1}} \tau_{1 \mathrm{xy}}^{2}\right.\right. \\
& +\frac{t_{2}}{E_{2}}\left(\sigma_{2 x}^{2}+\sigma_{2 y}^{2}-2 \nu_{2} \sigma_{2 x} \sigma_{2 y}\right)+\frac{2 t_{2}\left(1+\nu_{2}\right)}{E_{2}} \tau_{2 x y}^{2} \\
& +\frac{t_{3}}{E_{3}}\left(\sigma_{3 x}^{2}+\sigma_{3 y}^{2}-2 \nu_{3} \sigma_{3 x} \sigma_{3 y}\right)+\frac{2 t_{3}\left(1+\nu_{3}\right)}{E_{3}} \tau_{3 x y}^{2} \\
& \left.+\frac{\mathrm{h}_{1}}{\mathrm{G}_{1 \mathrm{xz}}} \tau_{1 \mathrm{xz}}^{2}+\frac{\mathrm{h}_{1}}{\mathrm{G}_{1 \mathrm{yz}}} \tau_{1 \mathrm{yz}}^{2}+\frac{\mathrm{h}_{2}}{\mathrm{G}_{2 \mathrm{xz}}} \tau_{2 \mathrm{xz}}^{2}+\frac{\mathrm{h}_{2}}{\mathrm{G}_{2 \mathrm{yz}}} \tau_{2 \mathrm{yz}}^{2}\right] \\
& +\lambda_{1}\left(M_{x}-t_{1} z_{1} \sigma_{1 x}-t_{2} z_{2} \sigma_{2 x}-t_{3} z_{3} \sigma_{3 x}\right) \\
& +\lambda_{2}\left(M_{y}-t_{1} z_{1} \sigma_{1 y}-t_{2} z_{2} \sigma_{2 y}-t_{3} z_{3} \sigma_{3 y}\right) \\
& +\lambda_{3}\left(M_{x y}-t_{1} z_{1} \tau_{1 x y}-t_{2} z_{2} \tau_{2 x y}-t_{3} z_{3} \tau_{3 x y}\right) \\
& +\lambda_{4}\left(\mathrm{Q}_{\mathrm{x}}-\mathrm{h}_{1} \tau_{1 \mathrm{xz}}-\mathrm{h}_{2} \tau_{2 \mathrm{xz}}\right) \\
& +\lambda_{5}\left(Q_{y}-h_{1} \tau 1 y z-h_{2}{ }_{2 y z}\right) \\
& +\lambda_{6}\left(t_{1} \sigma_{1 x}+t_{2} \sigma_{2 x}+t_{3} \sigma_{3 x}\right) \\
& +\lambda_{7}\left(t_{1} \sigma_{1 y}+t_{2} \sigma_{2 y}+t_{3} \sigma_{3 y}\right) \\
& +\lambda_{8}\left(t_{1} \tau_{1 x y}+t_{2} \tau_{2 x y}+t_{3} \tau_{3 x y}\right) \\
& +\alpha\left(M_{\mathrm{x}, \mathrm{x}}+\mathrm{M}_{\mathrm{xy}, \mathrm{y}}-\mathrm{Q}_{\mathrm{x}}\right)
\end{aligned}
$$




$$
\begin{aligned}
& +\beta\left(M_{y, y}+M_{x y, y}-Q_{y}\right) \\
& \left.+w\left(Q_{x, x}+Q_{y, y}+p\right)\right\} d x d y \\
& -\int_{0}^{b}\left(Q_{x} \zeta_{1}+M_{x y} \zeta_{2}+M_{x} \zeta_{3}\right)_{\substack{x=0 \\
x=a}} d y \\
& -\int_{0}^{a}\left(Q_{y} \zeta_{4}+M_{x y} \zeta_{5}+M_{y} \zeta_{6}\right)_{\substack{y=0 \\
y=b}} d x
\end{aligned}
$$

It is obvious that the Lagrangian multipliers $\alpha, \beta$ and $w$ have important physical meanings, i.e., $\alpha(\beta)$ the rotation of the face normal to the $\mathrm{x}(\mathrm{y})$-axis and $\mathrm{w}$ the transverse displacement of the sandwich plate. The rest of the set of Lagrangian multipliers are not of primary interest and can be eliminated by using the constraint conditions of equations (1) through (8).

In order to have extrema for the functional $V^{*}$ subjected to those constraint conditions, the first variation of the auxiliary functional must vanish, i.e., $\delta V^{* *}=0$ 。 For a system of stresses in static equilibrium, it can be proven ${ }^{(10)}$ that this is a minimum of $\mathrm{V}^{*}$, and that the condition $\delta \mathrm{V}^{* *}=0$ gives the set of compatibility conditions of deformations. Carrying out the first variation of $\mathrm{V}^{* *}$, integrating by parts and transforming the surface integrals to line integrals by Green's theorem, the set of Euler's equations is obtained as follow:

$$
\frac{t_{1}}{E_{1}}\left(\sigma_{1 x}-v_{1} \sigma_{1 y}\right)-t_{1} z_{1} \lambda_{1}+t_{1} \lambda_{6}=0
$$




$$
\begin{aligned}
& \frac{t_{1}}{E_{1}}\left(\sigma_{1 y}-\nu_{1} \sigma_{1 x}\right)-t_{1} z_{1} \lambda_{2}+t_{1} \lambda_{7}=0 \\
& \frac{t_{2}}{E_{2}}\left(\sigma_{2 x}-\nu_{2} \sigma_{2 y}\right)-t_{2} z_{2} \lambda_{1}+t_{2} \lambda_{6}=0
\end{aligned}
$$

$\frac{\mathrm{t}_{2}}{\mathrm{E}_{2}}\left(\sigma_{2 y}-\nu_{1} \sigma_{2 \mathrm{x}}\right)-\mathrm{t}_{2} \mathrm{z}_{2} \lambda_{2}+t_{2} \lambda_{7}=0$

$\frac{t_{3}}{E_{3}}\left(\sigma_{3 x}-\nu_{3} \sigma_{3 y}\right)-t_{3} z_{3} \lambda_{1}+t_{3} \lambda_{6}=0$

$\frac{t_{3}}{E_{3}}\left(\sigma_{3 y}-\nu_{3} \sigma_{3 x}\right)-t_{3} z_{3} \lambda_{2}+t_{3} \lambda_{7}=0$

$\frac{2 t_{1}\left(1+\nu_{1}\right)}{E_{1}} \tau_{1 x y}-t_{1} z_{1} \lambda_{3}+t_{1} \lambda_{8}=0$

$\frac{2 t_{2}\left(1+\nu_{2}\right)}{\mathrm{E}_{2}} \tau_{2 \mathrm{xy}}-\mathrm{t}_{2} \mathrm{z}_{2} \lambda_{3}+t_{2} \lambda_{8}=0$

$\frac{2 t_{3}\left(1+\nu_{3}\right)}{E_{3}} \tau_{3 x y}-t_{3} z_{3} \lambda_{3}+t_{3} \lambda_{8}=0$

$\frac{\mathrm{h}_{1}}{\mathrm{G}_{1 \mathrm{xz}}} \tau_{1 \mathrm{xz}}-\mathrm{h}_{1} \lambda_{4}=0$

$\frac{\mathrm{h}_{1}}{\mathrm{G}_{1 \mathrm{yz}}} \tau_{1 \mathrm{yz}}-\mathrm{h}_{1} \lambda_{5}=0$ 


$$
\begin{aligned}
& \frac{\mathrm{h}_{2}}{\mathrm{G}_{2 \mathrm{xz}}} \tau_{2 \mathrm{xz}}-\mathrm{h}_{2} \lambda_{4}=0 \\
& \frac{\mathrm{h}_{2}}{\mathrm{G}_{2 \mathrm{yz}}} \tau_{2 \mathrm{yz}}-\mathrm{h}_{2} \lambda_{5}=0
\end{aligned}
$$

and

$$
\begin{aligned}
& \lambda_{1}-\alpha, \mathrm{x}=0 \\
& \lambda_{2}-\beta_{, y}=0 \\
& \lambda_{3}-\left(\alpha_{, y}+\beta, \mathrm{x}\right)=0 \\
& \lambda_{4}-(\alpha+\mathrm{w}, \mathrm{x})=0 \\
& \lambda_{5}-(\beta+\mathrm{w}, \mathrm{y})=0
\end{aligned}
$$

This set of eighteen Euler's equations and those eleven constraint conditions constitute totally a system of twenty-nine equations with twenty-nine unknown quantities, i.e., eleven Lagrangian multipliers, thirteen stresses and five stress resultants and couples.

\subsection{Boundary Conditions}

In addition to the Euler's equations, a set of physical boundary conditions is also obtained by considering the independent vanishing of each term of the two line integrals in equation (15): 


$$
\begin{aligned}
& \text { At } x=0 \text { and } x=a, \\
& \zeta_{1}=w \\
& \zeta_{2}=\beta \\
& \zeta_{3}=\alpha \\
& \text { At } y=o \text { and } y=b, \\
& \zeta_{4}=w \\
& \zeta_{5}=\alpha \\
& \zeta_{6}=\beta
\end{aligned}
$$

\subsection{Stresses, Moments and Shear Forces}

Solving for the Lagrangian multipliers $\lambda_{1}, \lambda_{2}, \lambda_{3}, \lambda_{4}$ and $\lambda_{5}$ from equations (29), (30), (31), (32) and (33) in terms of the other set of Lagrangian multipliers $\lambda_{6}, \lambda_{7}, \alpha, \beta$ and $w$ and their first partial derivatives such that

$$
\begin{aligned}
& \lambda_{1}=\alpha, \mathrm{x} \\
& \lambda_{2}=\beta, \mathrm{y} \\
& \lambda_{3}=\alpha, \mathrm{y}+\beta, \mathrm{x} \\
& \lambda_{4}=\alpha+\mathrm{w}, \mathrm{x}
\end{aligned}
$$




$$
\lambda_{5}=\beta+w, y
$$

and substituting into equations (16) through (28), the stresses may be expressed as follow:

$$
\begin{aligned}
& \sigma_{1 \mathrm{x}}=\frac{\mathrm{E}_{1} \mathrm{z}_{1}}{1-\nu_{1}^{2}}\left(\alpha, \mathrm{x}+\nu_{1} \beta, \mathrm{y}\right)-\frac{\mathrm{E}_{1}}{1-\nu_{1}^{2}}\left(\lambda_{6}+\nu_{1} \lambda_{7}\right) \\
& \sigma_{1 y}=\frac{E_{1} z_{1}}{1-\nu_{1}^{2}}\left(\beta, y+\nu_{1} \alpha, x\right)-\frac{E_{1}}{1-\nu_{1}^{2}}\left(\lambda_{7}+\nu_{1} \lambda_{6}\right) \\
& \sigma_{2 x}=\frac{E_{2} z_{2}}{1-\nu_{2}^{2}}\left(\alpha, x+\nu_{2} \beta, y\right)-\frac{E_{2}}{1-\nu_{2}^{2}}\left(\lambda_{6}+\nu_{2} \lambda_{7}\right) \\
& \sigma_{2 y}=\frac{E_{2} z_{2}}{1-\nu_{2}^{2}}\left(\beta, y+\nu_{2} \alpha, x\right)-\frac{E_{2}}{1-\nu_{2}^{2}}\left(\lambda_{7}+\nu_{2} \lambda_{6}\right) \\
& \sigma_{3 \mathrm{x}}=\frac{\mathrm{E}_{3} \mathrm{z}_{3}}{1-\nu_{3}^{2}}\left(\alpha, \mathrm{x}+\nu_{3} \beta, \mathrm{y}\right)-\frac{\mathrm{E}_{3}}{1-\nu_{3}^{2}}\left(\lambda_{6}+\nu_{3} \lambda_{7}\right) \\
& \sigma_{3 y}=\frac{E_{3} z_{3}}{1-\nu_{3}^{2}}\left(\beta, y+\nu_{3} \alpha, x\right)-\frac{E_{3}}{1-\nu_{3}^{2}}\left(\lambda_{7}+\nu_{3} \lambda_{6}\right) \\
& \tau_{1 \mathrm{xy}}=\frac{\mathrm{E}_{1} \mathrm{z}_{1}}{2\left(1+\nu_{1}\right)}\left(\alpha_{, y}+\beta, \mathrm{x}\right)-\frac{\mathrm{E}_{1}}{2\left(1+\nu_{1}\right)} \lambda_{8} \\
& \tau_{2 \mathrm{xy}}=\frac{\mathrm{E}_{2} \mathrm{z}_{2}}{2\left(1+\nu_{2}\right)}(\alpha, \mathrm{y}+\beta, \mathrm{x})-\frac{\mathrm{E}_{2}}{2\left(1+\nu_{2}\right)} \lambda_{8}
\end{aligned}
$$




$$
\tau_{3 x y}=\frac{E_{3} z_{3}}{2\left(1+\nu_{3}\right)}\left(\alpha_{, y}+\beta, x\right)-\frac{E_{3}}{2\left(1+\nu_{3}\right)} \lambda_{8}
$$

and

$$
\begin{aligned}
& \tau_{1 \mathrm{xz}}=\mathrm{G}_{1 \mathrm{xz}}(\alpha+\mathrm{w}, \mathrm{x}) \\
& \tau_{1 \mathrm{yz}}=\mathrm{G}_{1 \mathrm{yz}}(\beta+\mathrm{w}, \mathrm{y}) \\
& \tau_{2 \mathrm{xz}}=\mathrm{G}_{2 \mathrm{xz}}(\alpha+\mathrm{w}, \mathrm{x}) \\
& \tau_{2 \mathrm{yz}}=\mathrm{G}_{2 \mathrm{yz}}(\beta+\mathrm{w}, \mathrm{y})
\end{aligned}
$$

Making use of equations (41) through (49), those constraint conditions of equations (6), (7), and (8), which characterize the problem of bending only, may be written as follow:

$$
\begin{aligned}
& c_{1} \lambda_{6}+c_{2} \lambda_{7}=c_{3} \alpha_{, x}+c_{4} \beta, y \\
& c_{2} \lambda_{6}+c_{1} \lambda_{7}=c_{4}{ }^{\alpha}, x+c_{3} \beta, y \\
& \left(c_{1}-c_{2}\right) \lambda_{8}=\left(c_{3}-c_{4}\right)(\alpha, y+\beta, x)
\end{aligned}
$$

where $c_{1}, c_{2}, c_{3}$ and $c_{4}$ are merely some constants of geometrical and material properties and are defined as

$$
c_{1}=\sum_{i} \frac{E_{i} t_{i}}{1-v_{i}^{2}}
$$




$$
\begin{aligned}
& c_{2}=\sum_{i} \frac{E_{i} t_{i} \nu_{i}}{1-\nu_{i}^{2}} \\
& c_{3}=\sum_{i} \frac{E_{i} t_{i} z_{i}}{1-\nu_{i}^{2}} \\
& c_{4}=\sum_{i} \frac{E_{i} t_{i} z_{i} \nu_{i}}{1-\nu_{i}^{2}}, i=1,2,3
\end{aligned}
$$

Solving for $\lambda_{6}, \lambda_{7}$ and $\lambda_{8}$ from equations (6a), (7a) and (8a) such that

$$
\begin{aligned}
& \lambda_{6}=\xi_{1} \alpha, x+\xi_{2} \beta, y \\
& \lambda_{7}=\xi_{2} \alpha, x+\xi_{1} \beta, y \\
& \lambda_{8}=\xi_{3}(\alpha, y+\beta, x)
\end{aligned}
$$

in which $\xi_{1}, \xi_{2}$ and $\xi_{3}$ are defined as

$$
\begin{aligned}
& \xi_{1}=\frac{c_{1} c_{3}-c_{2} c_{4}}{c_{1}^{2}-c_{2}^{2}} \\
& \xi_{2}=\frac{c_{1} c_{4}-c_{2} c_{3}}{c_{1}^{2}-c_{2}^{2}} \\
& \xi_{3}=\frac{c_{3}-c_{4}}{c_{1}-c_{2}}
\end{aligned}
$$


and substituting into equations (41) through (49), the stresses in all membranes can be obtained as follow:

$$
\begin{aligned}
& \sigma_{1 \mathrm{x}}=\frac{\mathrm{E}_{1}\left(\mathrm{z}_{1}-\xi_{1}-\nu_{1} \xi_{2}\right)}{1-\nu_{1}^{2}} \alpha, \mathrm{x}+\frac{\mathrm{E}_{1}\left(\nu_{1} z_{1}-\nu_{1} \xi_{1}-\xi_{2}\right)}{1-\nu_{1}^{2}} \beta, \mathrm{y} \\
& \sigma_{1 y}=\frac{E_{1}\left(z_{1}-\xi_{1}-\nu_{1} \xi_{2}\right)}{1-\nu_{1}^{2}} \beta_{, y}+\frac{E_{1}\left(\nu_{1} z_{1}-\nu_{1} \xi_{1}-\xi_{2}\right)}{1-\nu_{1}^{2}} \alpha, x \\
& \sigma_{2 x}=\frac{E_{2}\left(z_{2}-\xi_{1}-\nu_{2} \xi_{2}\right)}{1-\nu_{2}^{2}} \alpha, x+\frac{E_{2}\left(\nu_{2} z_{2}-\nu_{2} \xi_{1}-\xi_{2}\right)}{1-\nu_{2}^{2}} \beta, y \\
& \sigma_{2 y}=\frac{E_{2}\left(z_{2}-\xi_{1}-\nu_{2} \xi_{2}\right)}{1-\nu_{2}^{2}} \beta_{, y}+\frac{E_{2}\left(\nu_{2} z_{2}-\nu_{2} \xi_{1}-\xi_{2}\right)}{1-\nu_{2}^{2}} \alpha, x \\
& \sigma_{3 x}=\frac{E_{3}\left(z_{3}-\xi_{1}-\nu_{3} \xi_{2}\right)}{1-\nu_{3}^{2}} \alpha, x+\frac{E_{3}\left(\nu_{3} z_{3}-\nu_{3} \xi_{1}-\xi_{2}\right)}{1-\nu_{3}^{2}} \beta, y \\
& \sigma_{3 y}=\frac{E_{3}\left(z_{3}-\xi_{1}-\nu_{3} \xi_{2}\right)}{1-\nu_{3}^{2}} \beta, y+\frac{E_{3}\left(\nu_{3} z_{3}-\nu_{3} \xi_{1}-\xi_{2}\right)}{1-\nu_{3}^{2}} \alpha, x \\
& \tau_{1 \mathrm{xy}}=\frac{\mathrm{E}_{1}\left(\mathrm{z}_{1}-\xi_{3}\right)}{2\left(1+\nu_{1}\right)}\left(\alpha_{, y}+\beta_{, \mathrm{x}}\right) \\
& \tau_{2 \mathrm{xy}}=\frac{\mathrm{E}_{2}\left(\mathrm{z}_{2}-\xi_{3}\right)}{2\left(1+\nu_{2}\right)}(\alpha, \mathrm{y}+\beta, \mathrm{x}) \\
& \tau_{3 \mathrm{xy}}=\frac{E_{3}\left(\mathrm{z}_{3}-\xi_{3}\right)}{2\left(1+\nu_{3}\right)}(\alpha, y+\beta, \mathrm{x})
\end{aligned}
$$


Making substitution of these stresses into equations (1), (2), (3), (4) and (5), the moments and transverse shear forces can be expressed in terms of $\alpha, \beta, w$ and their partial derivatives ${ }^{(8)}$

$$
\begin{aligned}
& M_{x}=D\left(\alpha, x+\nu_{0} \beta, y\right) \\
& M_{y}=D\left(\beta, y+\nu_{0} \alpha, x\right) \\
& M_{x y}=D_{x y}(\alpha, y+\beta, x) \\
& Q_{x}=C_{x}(\alpha+w, x) \\
& Q_{y}=C_{y}(\beta+w, y)
\end{aligned}
$$

where $\mathrm{D}$ is the flexural rigidity of the sandwich plate and is defined by the following expression:

$$
D=\sum_{i} \frac{E_{i} t_{i} z_{i}\left(z_{i}-\xi_{1}-\nu_{i} \xi_{2}\right)}{1-\nu_{i}^{2}}, \quad i=1,2,3
$$

in which

$$
\nu_{0}=\frac{1}{D} \sum_{i} \frac{E_{i} t_{i} z_{i}\left(\nu_{i} z_{i}-\nu_{i} \xi_{1}-\xi_{2}\right)}{1-\nu_{i}^{2}}, i=1,2,3
$$

$D_{x y}$ the torsional rigidity of the sandwich plate and is defined as

$$
D_{x y}=\sum_{i} \frac{E_{i} t_{i} z_{i}\left(z_{i}-\dot{\xi}_{3}\right)}{2\left(1+\nu_{i}\right)}, i=1,2,3
$$


and

$$
\begin{array}{ll}
C_{x}=\sum_{j} h_{j} G_{j x z}, & j=1,2 \\
C_{y}=\sum_{j} h_{j} G_{j y z}, & j=1,2
\end{array}
$$

the shear rigidities of the sandwich plate.

\subsection{Specialization for Constant Poisson's Ratio}

The theory developed so far is of a general case of non-equal Poisson's ratio for each facing membrane. It has made the problem complicated not only in defining those plate constants but also in locating the so-called. "neutral surface" of the deformed structure.

In many instances, the values of Poisson's ratio may be very closely constant for materials with appreciably different moduli of elasticity. Assuming this to be the case, then, starting with the simplification of constants $\xi_{1}, \xi_{2}$ and $\xi_{3}$ in such a manner that

$$
\begin{aligned}
& \xi_{2}=0 \\
& \xi_{1}=\xi_{3}=z_{0}=\frac{\sum_{i} E_{i} t_{i} z_{i}}{\sum_{i} E_{i} t_{i}}, i=1,2,3
\end{aligned}
$$

and

$$
\begin{aligned}
& D=\frac{1}{1-\nu^{2}} \sum_{i} E_{i} t_{i} z_{i}\left(z_{i}-z_{o}\right) \\
& \nu_{0}=\frac{\nu D}{D}=\nu, \text { the common value of Poisson's ratio, }
\end{aligned}
$$




$$
D_{x y}=\frac{1-\nu}{2} D
$$

the stresses of membranes may be written as

$$
\begin{aligned}
& \sigma_{1 \mathrm{x}}=\frac{\mathrm{E}_{1}\left(\mathrm{z}_{1}-\mathrm{z}_{\mathrm{o}}\right)}{1-\nu^{2}}(\alpha, \mathrm{x}+\nu \beta, \mathrm{y}) \\
& \sigma_{1 y}=\frac{E_{1}\left(z_{1}-z_{o}\right)}{1-\nu^{2}}(\beta, y+\nu \alpha, x) \\
& \sigma_{2 x}=\frac{E_{2}\left(z_{2}-z_{o}\right)}{1-\nu^{2}}(\alpha, x+\nu \beta, y) \\
& \sigma_{2 y}=\frac{E_{2}\left(z_{2}-z_{o}\right)}{1-\nu^{2}}(\beta, y+\nu \alpha, x) \\
& \sigma_{3 \mathrm{x}}=\frac{\mathrm{E}_{3}\left(\mathrm{z}_{3}-\mathrm{z}_{\mathrm{o}}\right)}{1-\nu^{2}}(\alpha, \mathrm{x}+\nu \beta, \mathrm{y}) \\
& \sigma_{3 y}=\frac{E_{3}\left(z_{3}-z_{o}\right)}{1-\nu^{2}}(\beta, y+\nu \alpha, x) \\
& \tau_{1 \mathrm{xy}}=\frac{\mathrm{E}_{1}\left(\mathrm{z}_{1}-\mathrm{z}_{\mathrm{o}}\right)}{2(1+\nu)}\left(\alpha_{, y}+\beta, \mathrm{x}\right) \\
& \tau_{2 \mathrm{xy}}=\frac{\mathrm{E}_{2}\left(\mathrm{z}_{2}-\mathrm{z}_{\mathrm{o}}\right)}{2(1+\nu)}(\alpha, \mathrm{y}+\beta, \mathrm{x}) \\
& \tau_{3 \mathrm{xy}}=\frac{\mathrm{E}_{3}\left(\mathrm{z}_{3}-\mathrm{z}_{\mathrm{o}}\right)}{2(1+\nu)}(\alpha, y+\beta, \mathrm{x})
\end{aligned}
$$


where $\left(z_{i}-z_{0}\right)$ can be defined as the distance measured from the neutral surface to the middle plane of ith membrane. The bending and twisting moments are written as

$$
\begin{aligned}
& M_{x}=D(\alpha, x+\nu \beta, y) \\
& M_{y}=D(\beta, y+\nu \alpha, x) \\
& M_{x y}=\frac{1}{2}(1-\nu) D(\alpha, y+\beta, x)
\end{aligned}
$$

The system of twenty-nine equations with twenty-nine unknowns is reduced to that of three equations, i. e., equations (9), (10) and (11), with three unknowns $\alpha, \beta$ and $w$. Further reduction for finding the governing differential equations defining the bending behavior of the structure will be performed in the following chapter of this thesis. 


\section{CHAPTER III}

DERIVATION OF GOVERNING DIFFERENTIAL EQUATIONS

\subsection{Shear Forces}

After the specialization for constant Poisson's ratio, the crosssectional elements, moments and shear forces, are expressed in fairly simple forms, which have been shown by $S$. Cheng ${ }^{(8)}$ for a special case of sandwich plate construction with a single core and two identical facing membranes. It is understood that this is a reasonable assumption in practical purpose. Thus, in the following derivation, the Poisson's ratios of all membranes are specified to be constant, although the modulus of elasticity of each membrane may not be the same.

From equations (60) and (61), the Lagrangian multipliers $\alpha$ and $\beta$ may be found in terms of the transverse shear forces $Q_{X}$ and $Q_{y}$ such that

$$
\begin{aligned}
& \alpha=\frac{\mathrm{Q}_{\mathrm{x}}}{\mathrm{C}_{\mathrm{x}}}-\mathrm{w}, \mathrm{x} \\
& \beta=\frac{\mathrm{Q} \mathrm{y}}{\mathrm{C}_{\mathrm{y}}}-\mathrm{w}, \mathrm{y}
\end{aligned}
$$

Then, making use of these two expressions, equations (57), (58) and (59) can be written as follow: 


$$
\begin{aligned}
& M_{x}=D\left[\left(\frac{1}{C_{x}} Q_{x, x}+\frac{\nu_{o}}{C_{y}} Q_{y, y}\right)-\left(w_{, x x}+\nu_{o},{ }_{, y y}\right)\right] \\
& M_{y}=D\left[\left(\frac{1}{C_{y}} Q_{y, y}+\frac{\nu_{o}}{C_{x}} Q_{x, x}\right)-\left(w, y y+\nu_{o} w, x x\right)\right] \\
& M_{x y}=D_{x y}\left[\left(\frac{1}{C_{y}} Q_{x, y}+\frac{1}{C_{y}} Q_{y, x}\right)-2 w, x y\right]
\end{aligned}
$$

Utilizing equations (64), (65) and (66), equations (9) and (10) of moment equilibrium become

$$
\begin{aligned}
Q_{x}= & \frac{1}{C_{x}}\left(D Q_{x, x x}+D_{x y} Q_{x, y y}\right)+\frac{1}{C_{y}}\left(\nu_{0} D+D_{x y}\right) Q_{y, x y} \\
& -[D w, x x x \\
& {\left.\left[\nu_{o} D+2 D_{x y}\right) w, x y y\right] } \\
Q_{y}= & \frac{1}{C_{y}}\left(D Q_{y, y y}+D_{x y} Q_{y, x x}\right)+\frac{1}{C_{x}}\left(\nu_{o} D+D_{x y}\right) Q_{x, x y} \\
& -\left[D w, y y y+\left(\nu_{0} D+2 D_{x y}\right) w, x x y\right.
\end{aligned}
$$

For the case of specifying constant Poisson's ratio, these two expressions may be written as follow:

$$
\begin{aligned}
& Q_{x}=\frac{D}{C_{x}}\left[Q_{x, x x}+\left(\frac{1-\nu}{2}\right) Q_{x, y y}\right]+\frac{D}{C_{y}}\left(\frac{1+\nu}{2}\right) Q_{y, x y}-D \nabla^{2} w_{, x} \\
& Q_{y}=\frac{D}{C_{y}}\left[Q_{y, y y}+\left(\frac{1-\nu}{2}\right) Q_{y, x x}\right]+\frac{D}{C_{x}}\left(\frac{1+\nu}{2}\right) Q_{x, x y}-D \nabla^{2} w, y
\end{aligned}
$$


Differentiating equation (67a) with respect to $y$ and equation (68a) with respect to $x$, and subtracting yield

$$
\begin{aligned}
Q_{x, y}-Q_{y, x} & =\frac{D}{C}\left[Q_{x, x x y}+\left(\frac{1-\nu}{2}\right) Q_{x, y y y}\right]+\frac{D}{C_{y}}\left(\frac{1+\nu}{2}\right) Q_{y, x y y} \\
& -\frac{D}{C_{y}}\left[Q_{y, x y y}+\left(\frac{1-\nu}{2}\right) Q_{y, x x x}\right]-\frac{D}{C_{x}}\left(\frac{1+\nu}{2}\right) Q_{x, x x y}
\end{aligned}
$$

Differentiating equation (69) with respect to $y$, then,

$$
\begin{aligned}
Q_{x, y y}-Q_{y, x y} & =\frac{D}{C_{x}}\left[Q_{x, x x y y}+\left(\frac{1-\nu}{2}\right) Q_{x, y y y y}\right]+\frac{D}{C_{y}}\left(\frac{1+\nu}{2}\right) Q_{y, x y y y} \\
& -\frac{D}{C_{y}}\left[Q_{y, x y y y}+\left(\frac{1-\nu}{2}\right) Q_{y, x x x y}\right]-\frac{D}{C_{x}}\left(\frac{1+\nu}{2}\right) Q_{x, x x y y}
\end{aligned}
$$

Let equation (11) of the force equilibrium be written in a form such that

$$
Q_{y, y}=-\left(Q_{x, x}+p\right)
$$

then, by substitution, equation (70) becomes

$$
\begin{aligned}
K_{1} Q_{x, x x x x} & +\left(K_{1}+K_{2}\right) Q_{x, x x y y}+K_{2} Q_{x, y y y y}-\nabla^{2} Q_{x} \\
& =p_{, x}-K_{1} \nabla^{2} p_{, x}
\end{aligned}
$$

where $K_{1}$ and $K_{2}$ are some constants defined by the following expressions: 


$$
\begin{aligned}
& K_{1}=\frac{(1-\nu) D}{2 C_{y}} \\
& K_{2}=\frac{(1-\nu) D}{2 C_{x}}
\end{aligned}
$$

By the same procedure, the differential equation of $Q_{y}$ can be obtained as follows:

$$
\begin{aligned}
\mathrm{K}_{1} \mathrm{Q}_{\mathrm{y}, \mathrm{xxxx}} & +\left(\mathrm{K}_{1}+\mathrm{K}_{2}\right) \mathrm{Q}_{\mathrm{y}, \mathrm{xxyy}}+\mathrm{K}_{2} \mathrm{Q}_{\mathrm{y}}, \mathrm{yyyy}-\nabla^{2} \mathrm{Q}_{\mathrm{y}} \\
& =\mathrm{p}, \mathrm{y}-\mathrm{K}_{2} \nabla^{2} \mathrm{p}, \mathrm{y}
\end{aligned}
$$

Equation (71) and (74) may also be written in more compact forms such that

$$
\begin{aligned}
& \mathrm{K}_{2} \nabla^{4} \mathrm{Q}_{\mathrm{x}}+\left(\mathrm{K}_{1}-\mathrm{K}_{2}\right) \nabla^{2} \mathrm{Q}_{\mathrm{x}, \mathrm{xx}}-\nabla^{2} \mathrm{Q}_{\mathrm{x}}=\mathrm{p}_{, \mathrm{x}}-\mathrm{K}_{1} \nabla^{2} \mathrm{p}, \mathrm{x} \\
& \mathrm{K}_{1} \nabla^{4} \mathrm{Q}_{\mathrm{y}}+\left(\mathrm{K}_{2}-\mathrm{K}_{1}\right) \nabla^{2} \mathrm{Q}_{\mathrm{y}, \mathrm{yy}}-\nabla^{2} \mathrm{Q}_{\mathrm{y}}=\mathrm{p}_{, \mathrm{y}}-\mathrm{K}_{2} \nabla^{2} \mathrm{p}, \mathrm{y}
\end{aligned}
$$

where $\nabla^{4}$ is the biharmonic operator defined as

$$
\nabla^{4}=\nabla^{2} \nabla^{2}=\frac{\partial^{4}}{\partial x^{4}}+2 \frac{\partial^{4}}{\partial x^{2} \partial y^{2}}+\frac{\partial^{4}}{\partial y^{4}}
$$

for cartesian coordinates.

\subsection{Deflection Surface}

A governing differential equation defining the deflection surface $w(x, y)$ may be obtained by eliminating the shear forces from the force 
equilibrium equation. Differentiating equation (68a) with respect to $y$ and making use of equation (11a) yield

$$
\begin{aligned}
Q_{x, x}=\left[\frac{D}{C_{y}}\right. & \left.-\frac{D}{C_{x}}\left(\frac{1+\nu}{2}\right)\right] Q_{x, x y y}+\frac{D}{C_{y}}\left(\frac{1-\nu}{2}\right) Q_{x, x x x} \\
& +\frac{D}{C_{y}}\left[p, y y+\left(\frac{1-\nu}{2}\right) p, x x\right]-p+D \nabla^{2} w, y y
\end{aligned}
$$

Differentiating equation (67a) and also making use of equation (11a) give

$$
\begin{gathered}
Q_{x, x}=\frac{D}{C_{x}}\left(\frac{1-\nu}{2}\right) Q_{x, x y y}+\left[\frac{D}{C_{x}}-\frac{D}{C_{y}}\left(\frac{1+\nu}{2}\right)\right] Q_{x, x x x} \\
-\frac{D}{C_{y}}\left(\frac{1+\nu}{2}\right) p_{, x x}-D \nabla^{2} w, x x
\end{gathered}
$$

Subtracting equation (76) from equation (75) and making use of equations (72) and (73), a differential equation of shear force $Q_{x}$ may be obtained as follows:

$$
\nabla^{2} \mathrm{Q}_{\mathrm{x}, \mathrm{x}}=\frac{\mathrm{D}(1-\nu)}{2\left(\mathrm{~K}_{2}-\mathrm{K}_{1}\right)}\left(\nabla^{4} \mathrm{w}-\frac{\mathrm{p}}{\mathrm{D}}\right)+\frac{\mathrm{K}_{1}}{\mathrm{~K}_{2}-\mathrm{K}_{1}} \nabla^{2} \mathrm{p}
$$

By the same way, the differential equation of $Q_{y}$ may be obtained as follows:

$$
\nabla^{2} \mathrm{Q}_{\mathrm{y}, \mathrm{y}}=\frac{\mathrm{D}(1-\nu)}{2\left(\mathrm{~K}_{1}-\mathrm{K}_{2}\right)}\left(\nabla^{4} \mathrm{w}-\frac{\mathrm{p}}{\mathrm{D}}\right)+\frac{\mathrm{K}_{2}}{\mathrm{~K}_{1}-\mathrm{K}_{2}} \nabla^{2} \mathrm{p}
$$


Differentiating equation (71a) and making use of equation (77), a differential equation defining the transverse deflection of the plate is obtained;

$$
\begin{aligned}
& \mathrm{K}_{2} \nabla^{6} \mathrm{w}+\left(\mathrm{K}_{1}-\mathrm{K}_{2}\right) \nabla^{4} \mathrm{w}, \mathrm{xx}-\nabla^{4} \mathrm{w} \\
& =\frac{1}{\mathrm{D}}\left[-\frac{2 \mathrm{~K}_{1} \mathrm{~K}_{2}}{1-\nu} \nabla^{4} \mathrm{p}+\left(\mathrm{K}_{2}+\frac{2}{1-\nu} \mathrm{K}_{1}\right) \nabla^{2} \mathrm{p}\right. \\
& \left.\quad+\frac{1+\nu}{1-\nu}\left(\mathrm{K}_{2}-\mathrm{K}_{1}\right) \mathrm{p}_{。} \mathrm{xx}-\mathrm{p}\right]
\end{aligned}
$$

where $\nabla^{6}$ is a differential operator defined as

$$
\nabla^{6}=\nabla^{2} \nabla^{2} \nabla^{2}
$$

This equation may also be written in a form as follows:

$$
\begin{aligned}
& \mathrm{K}_{1} \nabla^{4} \mathrm{w}_{, \mathrm{xx}}+\mathrm{K}_{2} \nabla^{4} \mathrm{w}, \mathrm{yy}-\nabla^{4} \mathrm{w} \\
& =\frac{1}{\mathrm{D}}\left[-\frac{2 \mathrm{~K}_{1} \mathrm{~K}_{2}}{1-\nu} \nabla^{4} \mathrm{p}+\left(\mathrm{K}_{2}+\frac{2}{1-\nu} \mathrm{K}_{1}\right) \nabla^{2} \mathrm{p}\right. \\
& \left.\quad+\frac{1+\nu}{1-\nu}\left(\mathrm{K}_{2}-\mathrm{K}_{1}\right) \mathrm{p}, \mathrm{xx}-\mathrm{p}\right]
\end{aligned}
$$

or in a form, which can be compared with the homogeneous plate equation, such that

$$
\begin{aligned}
(1- & \left.\mathrm{K}_{1} \frac{\partial^{2}}{\partial \mathrm{x}^{2}}-\mathrm{K}_{2} \frac{\partial^{2}}{\partial \mathrm{y}^{2}}\right) \nabla^{4} \mathrm{w}=\left[1-\left(\mathrm{K}_{1}+\frac{2 \mathrm{~K}_{2}}{1-\nu}\right) \frac{\partial^{2}}{\partial \mathrm{x}^{2}}\right. \\
& \left.-\left(\mathrm{K}_{2}+\frac{2 \mathrm{~K}_{1}}{1-\nu}\right) \frac{\partial^{2}}{\partial \mathrm{y}^{2}}+\frac{2 \mathrm{~K}_{1} \mathrm{~K}_{2}}{1-\nu} \nabla^{4}\right] \frac{\mathrm{p}}{\mathrm{D}}
\end{aligned}
$$


This is a sixth-order linear partial differential equation defining the transverse deflection of the sandwich plate for the case of specializing the Poisson's ratios of all membranes to be constant.

\subsection{Reduction to the Case of Isotropic Cores}

For the case that all core materials are isotropic, the constants $K_{1}$ and $K_{2}$ are identical, and are defined as

$$
\mathrm{K}_{1}=\mathrm{K}_{2}=\mathrm{K}=\frac{(1-\nu) \mathrm{D}}{2 \mathrm{C}}
$$

where

$$
C=\sum_{j} h_{j} G_{j x z}=\sum_{j} h_{j} G_{j y z}
$$

in which $j$ designates the number of core. The differential equations (71a) and (74a) of shears become

$$
\begin{aligned}
& \nabla^{2} Q_{x}=-p, x \\
& \nabla^{2} Q_{y}=-p, y
\end{aligned}
$$

The sixth-order differential equation (81) defining the transverse deflection $w$ reduces to a fourth-order linear differential equation as follows:

$$
\nabla^{4} \mathrm{w}=\frac{\mathrm{p}}{\mathrm{D}}-\frac{1}{\mathrm{C}} \nabla^{2} \mathrm{p}
$$


For those loading conditions which make the second term of the righthand side of equation (86) vanish, the equation becomes exactly the one of homogeneous plate. This result has been shown previously by E. Reissner ${ }^{(11)}$ and $\mathrm{S}$. Cheng ${ }^{(8)}$ for a particular case of plate with a single core and two identical facing membranes. 


\section{CHAPTER IV \\ A SIMPLY SUPPORTED RECTANGULAR PLATE WITH ORTHOTROPIC CORES}

The problem of bending of a simply supported rectangular sandwich plate with orthotropic cores subjected to a system of uniformly distributed loads is considered (Fig. 3). The plate is assumed to be constructed in such a manner that all the membranes are of the same material and cores are arbitrary. Thus, those constants D, $\mathrm{C}_{\mathrm{X}}$ and $\mathrm{C}_{\mathrm{y}}$ can be calculated by those equations defined in this thesis. Since the load is constant over the entire structure, the differential equation (81) defining the transverse deflection becomes

$$
\left(1-K_{1} \frac{\partial^{2}}{\partial x^{2}}-K_{2} \frac{\partial^{2}}{\partial y^{2}}\right) \nabla^{4} w=\frac{p}{D}
$$

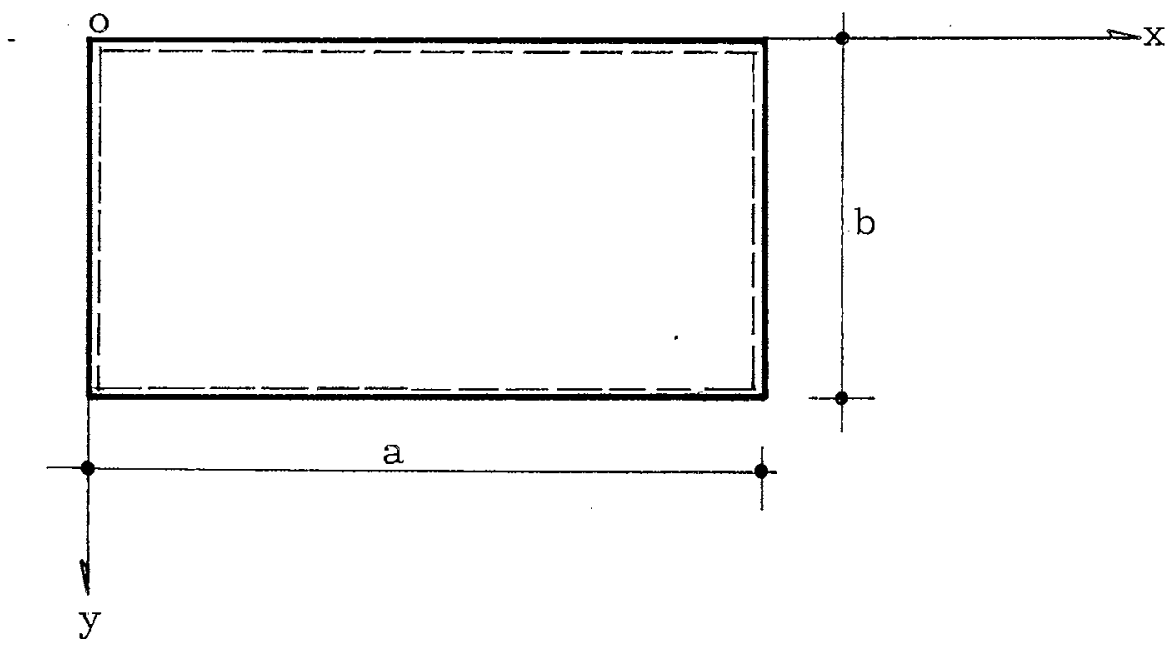

FIG. 3 A SIMPLY SUPPORTED RECTANGULAR PLATE 
For a Navier's type of solution, the deflection surface may be assumed in such a form that

$$
\mathrm{w}=\sum_{\mathrm{m}} \sum_{\mathrm{n}} \mathrm{W}_{\mathrm{mn}} \sin \frac{\mathrm{m} \pi \mathrm{x}}{\mathrm{a}} \sin \frac{\mathrm{n} \pi \mathrm{y}}{\mathrm{b}}, \begin{aligned}
\mathrm{m} & =1,2,3, \ldots, \infty \\
\mathrm{n} & =1,2,3, \ldots, \infty
\end{aligned}
$$

Then, the loading function $p(x, y)$ may be represented by the shape of deflection surface such that

$$
\mathrm{p}(\mathrm{x}, \mathrm{y})=\sum_{m} \sum_{n} P_{m n} \sin \frac{\mathrm{m} \pi \mathrm{x}}{\mathrm{a}} \sin \frac{\mathrm{n} \pi \mathrm{y}}{\mathrm{b}}, \begin{aligned}
\mathrm{m} & =1,2,3, \ldots, \infty(89) \\
\mathrm{n} & =1,2,3, \ldots, \infty
\end{aligned}
$$

where $\mathrm{P}_{\mathrm{mn}}$ can be evaluated as follows:

$$
P_{m n}=\frac{4}{a b} \int_{0}^{a} \int_{0}^{b} p(x, y) \sin \frac{m \pi x}{a} \sin \frac{n \pi y}{b} d x d y
$$

which becomes

$$
\mathrm{P}_{\mathrm{m}}=\frac{16 \mathrm{p}}{\mathrm{mn} \pi^{2}}, \begin{aligned}
\mathrm{m} & =1,3,5, \ldots, \infty \\
\mathrm{n} & =1,3,5, \ldots, \infty
\end{aligned}
$$

for constant $p$ over the entire region. Making substitution of equation (88) into equation (87), the coefficient $W_{m n}$ may be solved in terms of the known coefficient of loading function $P_{m n}$ such that

$$
W_{m n}=\frac{P_{m n}}{D\left[\left(\frac{m \pi}{a}\right)^{2}+\left(\frac{n \pi}{b}\right)^{2}\right]^{2}\left[1+K_{1}\left(\frac{m \pi}{a}\right)^{2}+K_{2}\left(\frac{n \pi}{b}\right)^{2}\right]}
$$

or, in a symbolic form: 


$$
\mathrm{W}_{\mathrm{mn}}=\mathrm{W}_{\mathrm{mn}}^{*} \frac{\mathrm{P}_{\mathrm{mn}}}{\mathrm{D}}
$$

where

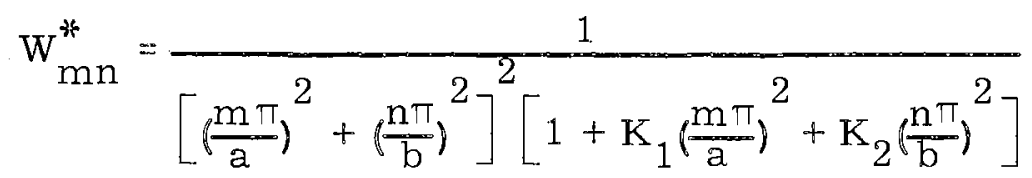

Thus, the deflection surface becomes

$$
w=\frac{1}{D} \sum_{m} \sum_{n} w_{m n}^{*} P_{m n} \sin \frac{m \pi x}{a} \sin \frac{n \pi y}{b}
$$

which may be written in a form that can be compared with the Navier ${ }^{i} \mathbf{s}$ solution of the homogeneous plate subjected to uniformly distributed loa ds:

$$
w=\frac{16 p}{\pi^{6} D} \sum_{m} \sum_{n} \frac{\sin \frac{m \pi x}{a} \sin \frac{n \pi y}{b}}{m n\left[\left(\frac{m}{a}\right)^{2}+\left(\frac{n}{b}\right)^{2}\right]^{2}\left[1+K_{1}\left(\frac{m \pi}{a}\right)^{2}+K_{2}\left(\frac{n \pi}{b}\right)^{2}\right]}
$$

where $m$ and $n$ are positive odd integers.

Using equations (77), (78) and (88), the shear forces $Q_{X}$ and Q $y$ may be assumed to have forms as follow:

$$
\begin{aligned}
& Q_{x}=\sum_{m} \sum_{n} A_{m n} \cos \frac{m \pi x}{a} \sin \frac{n \pi y}{b} \\
& Q_{y}=\sum_{m} \sum_{n} B_{m n} \sin \frac{m \pi x}{a} \cos \frac{n \pi y}{b}, \begin{array}{r}
m=1,2, \ldots, \infty \\
n=1,2, \ldots, \infty
\end{array}
\end{aligned}
$$


Substituting equations (88) and (95) into equation (77), and equations (88) and (96) into equation (78), the series coefficients $A_{m n}$ and $B_{\mathrm{mn}}$ are obtained:

$$
\begin{aligned}
& A_{m n}=\left(\frac{a}{m \pi}\right)\left[\frac{1-\nu}{2\left(\mathrm{~K}_{2}-\overline{\left.K_{1}\right)}\right.}\right] \gamma_{m n} P_{m n} \\
& B_{m n}=-\left(\frac{b}{n \pi}\right)\left[\frac{1-\nu}{2\left(\mathrm{~K}_{2}-\bar{K}_{1}\right)}\right] \gamma_{m n} P_{m n}
\end{aligned}
$$

where

$$
Y_{m n}=\frac{1}{\left(\frac{m \pi}{a}\right)^{2}+\left(\frac{n \pi}{b}\right)^{2}}\left[\frac{K_{1}\left(\frac{m \pi}{a}\right)^{2}+K_{2}\left(\frac{n \pi}{b}\right)^{2}}{1+K_{1}\left(\frac{m \pi}{a}\right)^{2}+K_{2}\left(\frac{n \pi}{b}\right)^{2}}\right]
$$

Rewriting equations (62) and (63) in terms of constants $K_{1}$ and $K_{2}$ :

$$
\begin{aligned}
& \alpha=\frac{2 \mathrm{~K}_{2}}{\mathrm{D}(1-\nu)} \mathrm{Q}_{\mathrm{x}}-\mathrm{w}, \mathrm{x} \\
& \beta=\frac{2 \mathrm{~K}_{1}}{\mathrm{D}(1-\mathrm{v})} \mathrm{Q}_{\mathrm{y}}-\mathrm{w}, \mathrm{y}
\end{aligned}
$$

and making use of equations (88), (95) and (96), the Lagrangian multipliers $\alpha$ and $\beta$ are obtained:

$$
\begin{aligned}
& \alpha=\sum_{m} \sum_{n} \alpha_{m n}^{*} \cos \frac{m \pi x}{a} \sin \frac{n \pi y}{b} \\
& \beta=\sum_{m} \sum_{n} \beta_{m n}^{*} \sin \frac{m \pi x}{a} \cos \frac{n \pi y}{b}
\end{aligned}
$$


where $\alpha_{m n}^{*}$ and $\beta_{m n}^{*}$ are determined by those known coefficients $A_{m n}, B_{m n}$ and $W_{m n}$ by the equations as follow:

$$
\begin{aligned}
& \alpha_{m n}^{*}=\frac{2 K_{2}}{D(1-\nu)} A_{m n}-\left(\frac{m \pi}{a}\right) W_{m n} \\
& \beta_{m n}^{*}=\frac{2 K_{1}}{D(1-\nu)} B_{m n}-\left(\frac{n \pi}{b}\right) W_{m n}
\end{aligned}
$$

or, in terms of $\mathrm{P}_{\mathrm{mn}}$ such that

$$
\begin{aligned}
& \alpha_{m n}^{*}=\left[\left(\frac{a}{m \pi}\right)\left(\frac{K_{2}}{K_{2}-\bar{K}_{1}}\right) Y_{m n}-\left(\frac{m \pi}{a}\right) W_{m n}^{*}\right] \frac{P_{m n}}{D} \\
& \beta_{m n}^{*}=-\left[\left(\frac{b}{n \pi}\right)\left(\frac{K_{1}}{K_{2}-\bar{K}_{1}}\right) Y_{m n}+\left(\frac{n \pi}{b}\right) W_{m n}^{*}\right] \frac{P_{m n}}{D}
\end{aligned}
$$

In these expressions, the constants $K_{1}$ and $K_{2}$ cannot be the same, that is due to the fact that the differential equations for orthotropic case and isotropic case are distinct. These solutions do satisfy the boundary conditions of a simply supported plate, i.e., $w=0$, $M_{x}=0$ and $\beta=0$ at the edges $x=0$ and $x=a$ and $w=0, M_{y}=0$ and $\alpha=0$ at the edges $y=0$ and $y=b$ 。 


\section{CHAPTER V \\ SUMMARY AND CONCLUSIONS}

The purpose of this thesis is to develop a theory defining the bending behavior of the multi-layer sandwich plates, which are constructed in such a manner that those assumptions stated previously are satisfied, due to a general type of externally applied load normal to the plane of structures. The development of the theory falls mainly upon the formulation of the functional of complementary energy of the system, minimizing process and the elimination of some additional Lagrangian multipliers introduced for the constraint conditions. The problem is formulated in a complete Lagrange form with all stresses as dependent variables, which are functions of two independent variables locating the position on the plane of structure. This type of formulation has not been shown previously。

It is found in this investigation that, a "neutral surface" cannot be properly defined for the case that the facing membranes have completely different elastic properties. However, it is understood that the difference of values of Poission's ratio for different materials with appreciably different moduli of elasticity is small. Thus, an additional as sumption specifying the constant Poisson's ratio is made in this investigation.

After the specialization for the constant Poisson's ratio, a sixth-order partial differential equation governing the transverse deflection and two supplementary equations governing the transverse 
shear forces are obtained. This result has generalized the "membrane facings" theory of sandwich construction which was originated by E. Reissner (1), (11), (12).

A simple example of a sandwich plate with simply supported edges is solved by the Navier's approach to illustrate the application of the presented theory.

The governing differential equation defining the transverse vibration, without rotatory effect, can be directly obtained by introducing the inertia force to replace the static transverse load p. The presented formulation may also be extended to develop the theory defining the buckling of the multi-layer sandwich plates. 


\section{BIBLIOGRAPHY}

1. Reissner, E., "On Bending of Elastic Plates," Quarterly of Applied Mathematics, Vol.5, 1947.

2. Hoff, N. J., "Bending and Buckling of Rectangular Sandwich Plates," NACA TN 2225, 1950.

3. Libove, C. and S. B. Batdorf, "A General Small-Deflection Theory for Flat Sandwich Plates," NACA TN 1526, 1948.

4. Eringen, A. C., "Bending and Buckling of Rectangular Sandwich Plates," Proceedings, First U. S. Congress of Applied Mechanics, 1951 .

5. Yu, Y. Y., "A New Theory of Sandwich Plates - One-Dimensional Case," Journal of Applied Mechanics, Transactions, ASME, Vol. 81, 1959.

6. Yu, Y. Y., "Flexural Vibrations of Elastic Sandwich Plates," Journal of Aero'Space Sciences, Vol。27, 1960.

7. Yu, Y. Y., "Forced Flexural Vibrations of Sandwich Plates in Plane Strain," Journal of Applied Mechanics, Transactions, ASME, Vol。82, 1960。

8. Cheng, S., "On the Theory of' Bending of Sandwich Plates," Proceedings, Fourth U. S. Congress of Applied Mechanics, 1962 。

9. Chang, C. C. and I. K. Ebicoglu, "Elastic Instability of Rectangular Sandwich Panel of Orthotropic Core with Different Face Thicknesses and Materials, " Journal of Applied Mechanics, Transactions, ASME, V01.82, 1960.

10. Sokolnikoff, I. S., Mathematical Theory of Elasticity, McGrawHill Book Co。, Inc。, New York, 1956, pp。387-390。

11. Reissner, E. "Small Bending and Stretching of Sandwich-type Shells," NACA TN 1832, 1949 。

12. Reissner, E., "Finite Deflections of Sandwich Plates," Journal of the Aeronautical Sciences, Vol. 15, 1948. 
APPENDIX

AN APPROXIMATE THEORY

\section{A-1 Derivation}

By the principle of superposition for small deformations, it is possible to separate the transverse deflection into two parts: one is due to the bending and the other due to the shear deformation. Observing equations (57), (58) and (59), the deflection due to bending may be introduced in such a manner that

$$
\begin{aligned}
& \alpha=-w_{b, x} \\
& \beta=-w_{b, y}
\end{aligned}
$$

where $w_{b}$ designates the flexural part of the transverse deflection. Then, equations (57), (58), (59), (60) and (61) can be written in the following forms:

$$
\begin{aligned}
& M_{x}=-D\left(w_{b, x x}+\nu_{o} w_{b, y y}\right) \\
& M_{y}=-D\left(w_{b, y y}+\nu_{o} w_{b, x x}\right) \\
& M_{x y}=-2 D_{x y} w_{b, x y} \\
& Q_{x}=C_{x}\left(w, x-w_{b, x}\right) \\
& Q_{y}=C_{y}\left(w, y-w_{b, y}\right)
\end{aligned}
$$


Substitution of equations (A6) and (A7) into equation (11) of the force equilibrium yields

$$
\mathrm{K}_{1} \mathrm{w}_{\mathrm{S}, \mathrm{xx}}+\mathrm{K}_{2} \mathrm{w}_{\mathrm{s}, \mathrm{yy}}=-\left(\frac{2 \mathrm{~K}_{1} \mathrm{~K}_{2}}{1-\nu}\right) \frac{\mathrm{p}}{\mathrm{D}}
$$

where $K_{1}$ and $K_{2}$ are defined by equations (72) and (73), and $\mathrm{w}_{\mathrm{S}}$ is the part of deflection due to shear and is defined as follows:

$$
\mathrm{w}_{\mathrm{s}}=\mathrm{w}-\mathrm{w}_{\mathrm{b}}
$$

Making use of equations (A3), (A4) and (A5), equations (9) and (10) of the moment equilibrium may be written as

$$
\begin{aligned}
& C_{x} w_{s, x}=-D\left(w_{b, x x x}+v_{o} w_{b, x y y}\right)-2 D_{x y} w_{b, x y y} \\
& C_{y} w_{s, y}=-D\left(w_{b, y y y}+\nu_{o} w_{b, x x y}\right)-2 D_{x y} w_{b ; x x y}
\end{aligned}
$$

Differentiating equations (A10) with respect to $\mathrm{x}$ and (A11) with respect to $\mathrm{y}$ and adding together yield

$$
\begin{aligned}
& \mathrm{Dw}_{\mathrm{b}, \mathrm{xxxx}}+2\left(2 \mathrm{D}_{\mathrm{xy}}+\nu_{\mathrm{o}} \mathrm{D}\right) \mathrm{w}_{\mathrm{b}, \mathrm{xxyy}}+\mathrm{D} \mathrm{w}_{\mathrm{b}, \text { yyyy }} \\
& =-\left(\mathrm{C}_{\mathrm{x}} \mathrm{w}_{\mathrm{s}, \mathrm{xx}}+\mathrm{C}_{\mathrm{y}} \mathrm{w}_{\mathrm{s}, \mathrm{yy}}\right)
\end{aligned}
$$

Replacing $\mathrm{C}_{\mathrm{x}}$ and $\mathrm{C}_{\mathrm{y}}$ by $\mathrm{K}_{1}$ and $\mathrm{K}_{2}$ and using equation (A8), equation (A12) becomes

$$
\mathrm{D}_{\mathrm{b}, \mathrm{xxxx}}+2\left(2 \mathrm{D}_{\mathrm{xy}}+\nu_{\mathrm{o}} \mathrm{D}\right) \mathrm{w}_{\mathrm{b}, \mathrm{xxyy}}+\mathrm{D}_{\mathrm{b}, \text { yyyy }}=\mathrm{p}
$$

which may be written as 


$$
\nabla^{4} \mathrm{w}_{\mathrm{b}}=\frac{\mathrm{p}}{\mathrm{D}}
$$

for the case of specifying the constant Poisson's ratio for all membranes. For the case that all core materials are isotropic, equation (A8) is reduced to a Poisson's equation:

$$
\nabla^{2} \mathrm{w}_{\mathrm{s}}=-\frac{\mathrm{p}}{\mathrm{C}}
$$

where $\mathrm{C}$ is the constant defined by equation (83). Making operation on equation (A 15) by the Laplacian operator and adding to equation (A 14) yield

$$
\nabla^{4} \mathrm{w}=\frac{\mathrm{p}}{\mathrm{D}}-\frac{1}{\mathrm{C}} \nabla^{2} \mathrm{p}
$$

which has been shown previously in Chapter III as equation (86) of this thesis.

For the case with orthotropic cores, the sixth-order equation governing the transverse deflection now is approximated by equations (A 8) and (A14). It is also shown that, for the case with isotropic cores, this approximate theory becomes exact in the sense of previous derivation.

\section{A-2 Comparison of Solutions}

The problem considered previously in Chapter IV of a simply supported rectangular sandwich plate is solved by the approximate theory derived in this appendix. The solutions for the $\mathrm{w}_{\mathrm{b}}$ and $\mathrm{w}_{\mathrm{s}}$ are assumed to have the forms as follow: 


$$
\begin{aligned}
& \mathrm{w}_{\mathrm{b}}=\sum_{\mathrm{m}} \sum_{\mathrm{n}} \mathrm{w}_{\mathrm{bmn}} \sin \frac{\mathrm{m} \pi \mathrm{x}}{\mathrm{a}} \sin \frac{\mathrm{n} \pi \mathrm{y}}{\mathrm{b}} \\
& \mathrm{w}_{\mathrm{s}}=\sum_{\mathrm{m}} \sum_{\mathrm{n}} \mathrm{w}_{\mathrm{smn}} \sin \frac{\mathrm{m} \pi \mathrm{x}}{\mathrm{a}} \sin \frac{\mathrm{n} \pi \mathrm{y}}{\mathrm{b}}
\end{aligned}
$$

The loading function $\mathrm{p}(\mathrm{x}, \mathrm{y})$ is also represented by the shape of the deflection surface that

$$
p(x, y)=\sum_{m} \sum_{n} P_{m n} \sin \frac{m \pi x}{a} \sin \frac{n \pi y}{b}
$$

where $P_{m n}$ is evaluated by the same way described previously in Chapter IV. Making substitutions of equation (A17) into (A14) and (A18) into (A8) respectively, yield

$$
\begin{aligned}
& \mathrm{W}_{\mathrm{bmn}}=\frac{\mathrm{P}_{\mathrm{mn}}}{\mathrm{D}\left[\left(\frac{\mathrm{m} \pi}{\mathrm{a}}\right)^{2}+\left(\frac{\mathrm{n})^{2}}{\mathrm{~b}}\right)^{2}\right]^{2}} \\
& \mathrm{~W}_{\mathrm{smn}}=\frac{\frac{2 \mathrm{~K}_{1} \mathrm{~K}_{2}}{1-\nu}}{\mathrm{K}_{1}\left(\frac{\mathrm{m} \pi}{\mathrm{a}}\right)^{2}+\mathrm{K}_{2}\left(\frac{\mathrm{n} \pi}{\mathrm{b}}\right)^{2}}\left(\frac{\mathrm{P}_{\mathrm{mn}}}{\mathrm{D}}\right)
\end{aligned}
$$

Thus, the solution of the total deflection is

$$
\mathrm{w}=\frac{1}{\mathrm{D}} \sum_{\mathrm{m}} \sum_{\mathrm{n}} \mathrm{W}_{\mathrm{mn}}^{* * *} P_{m n} \sin \frac{\mathrm{m} \pi \mathrm{x}}{\mathrm{a}} \sin \frac{\mathrm{n} \pi \mathrm{y}}{\mathrm{b}}
$$

where $\mathrm{W}_{\mathrm{mn}}^{* *}$ is defined as follows:

$$
W_{m n}^{* *}=\frac{1}{\left[\left(\frac{m \pi}{a}\right)^{2}+\left(\frac{n \pi}{b}\right)^{2}\right]}+\frac{\frac{2 K_{1} K_{2}}{1-\nu}}{K_{1}\left(\frac{m \pi}{a}\right)^{2}+K_{2}\left(\frac{n \pi}{b}\right)^{2}}
$$


Designating the ratio between the constants $K_{1}$ and $K_{2}$ such that

$$
\eta=\frac{\mathrm{K}_{2}}{\mathrm{~K}_{1}}=\frac{\mathrm{C}_{\mathrm{y}}}{\mathrm{C}_{\mathrm{x}}}
$$

then, $\mathrm{W}_{\mathrm{mn}}^{* * *}$ becomes

$$
\mathrm{W}_{\mathrm{mn}}^{* * *}=\frac{1}{\left[\left(\frac{\mathrm{m} \pi}{\mathrm{a}}\right)^{2}+\left(\frac{\mathrm{n} \pi}{\mathrm{b}}\right)^{2}\right]^{2}}+\frac{\frac{2 \eta \mathrm{K}_{1}}{1-\nu}}{\left(\frac{\mathrm{m} \pi}{\mathrm{a}}\right)^{2}+\eta\left(\frac{\mathrm{n} \pi}{\mathrm{b}}\right)^{2}}
$$

The Lagrangian multipliers used to calculate the moments and the shear forces are obtained by substituting equations (A17) and (A18) into equations (A1), (A2), (A6) and (A7):

$$
\begin{aligned}
& \alpha=-\frac{1}{D} \sum_{m} \sum_{n} \frac{\left(\frac{m \pi}{a}\right) P_{m n}}{\left[\left(\frac{m \pi}{a}\right)^{2}+\left(\frac{n \pi^{2}}{b}\right]^{2}\right.} \cos \frac{m \pi x}{a} \sin \frac{n \pi y}{b} \\
& \beta=-\frac{1}{D} \sum_{m} \sum_{n} \frac{\left(\frac{n \pi}{b}\right) P_{m n}}{\left[\left(\frac{m \pi}{a}\right)^{2}+\left(\frac{n \pi}{b}\right)^{2}\right]^{2}} \sin \frac{m \pi x}{a} \cos \frac{n \pi y}{b} \\
& Q_{x}=\sum_{m} \sum_{n} \frac{\left(\frac{m \pi}{a}\right) K_{1}}{K_{1}\left(\frac{m \pi}{a}\right)^{2}+K_{2}\left(\frac{n \pi}{b}\right)^{2}} \cos \frac{m \pi x}{a} \sin \frac{n \pi y}{b}
\end{aligned}
$$

and

$$
Q_{y}=\sum_{m} \sum_{n} \frac{\left(\frac{n \pi}{b}\right) K_{2}}{K_{1}\left(\frac{m \pi}{a}\right)^{2}+K_{2}\left(\frac{n \pi}{b}\right)} \sin \frac{m \pi x}{a} \cos \frac{n \pi y}{b}
$$


Solutions of these forms do satisfy the boundary conditions described in Chapter IV.

Comparison between the solutions of the approximate theory and the "exact" theory shows that the approximate theory is valid only for the case of isotropic cores or in case the deformations due to shear are negligibly small. This conclusion proves that the assumptions made by T. E. Falgout* are not true, in general.

* T. E. Falgout, "A Differential Equation of Free Transverse Vibrations of Isotropic Sandwich Plates, "Developments in Mechanics, Vol. 1, Proceedings of the Seventh Midwestern Mechanics Conference, 1961. 


\author{
VITA \\ BOEN-DAR LIAW \\ Candidate for the Degree of \\ Doctor of Philosophy
}

Thesis: THEORY OF BENDING OF MULTI-LAYER SANDWICH PLATES

Major Field: Engineering

Biographical:

Personal Data: Born October 19, 1937, in Hsiro, Taiwan, China, the son of H. S. and Y. C. Liaw.

Education: Graduated from Chien-Kou Middle Shcool, Taipei, Taiwan, in June, 1953, Taipei Institute of Technology, Taipei, Taiwan, in June, 1958; one year undergraduate study in Civil Engineering at the Oklahoma State University. January, 1961 to January, 1962; received the Master of Science degree from the Oklahoma State University, in May, 1963, with a major in Civil Engineering; completed the requirements for the degree of Doctor of Philosophy in August, 1965.

Professional Experience: Engineering Officer in Chinese Air Force, 1958-60. Junior Civil Engineer at the Taiwan Electric Power Company, Taipei, Taiwan, 1960. Graduate Assistant at the Oklahoma State University, 1962-65.

Professional Organization: Associate Member of the American Society of Civil Engineers. 